\title{
RESEARCH ON EFFECT OF SLIDING BETWEEN HOOP CABLE AND CABLE-STRUT JOINT ON BEHAVIOR OF SUSPEN-DOME STRUCTURES
}

\author{
Hongbo Liu ${ }^{1}$ and Zhihua Chen ${ }^{1,2, *}$ \\ ${ }^{1}$ Department of Civil Engineering, Tianjin University, Tianjin 300072, China \\ 2. Tianjin Key Laboratory of Civil Engineering Structures and New Materials, Tianjin 300072, China \\ *(Corresponding author: E-mail: zhchen@tju.edu.cn)
}

Received: 1 August 2011; Revised: 5 October 2011; Accepted: 21 November 2011

\begin{abstract}
For suspen-dome structures, the construction process is very complex and may have an effect on its structural behavior during service time. During construction, a remarkable pre-stressing loss may be induced by sliding friction between hoop cable and cable-strut joint, and the sliding friction can be any value in construction stage and service time. In this paper, the effect of pre-stressing loss and sliding friction during construction on the structural behavior of suspen-dome structures is investigated. The analysis results show that the construction process has a remarkable effect on the structural behavior of suspen-dome structures and a security risk can be induced by it. Therefore, it is suggested that the construction process should be considered in the design process of suspen-dome structures.
\end{abstract}

Keywords: Suspen-dome structures, Construction process, Pre-stressing loss, Sliding friction, Structural behavior

\section{INTRODUCTION}

Weight reduction and span increase of structures are typical tendencies in the development of spatial structures, which can be accomplished by the application of new high-strength materials. Steel cable is a high-strength material. It has been widely introduced into traditional steel structures, such as beams, trusses, single-layer lattice shell and barrel vault structure and so on, forming beam string structures [1], truss string structures [1] and suspen-dome structures [2] and cable supported barrel vault structure [3] and so on. Suspen-dome structure is a pre-stressed spatial steel structure and presented by Kawaguchi [2]. It has a good structural behavior under loading and has been widely used in sport facilities, convention \& exhibition centers in Japan and China [4,5].

Many investigations have been carried out to reveal the structural behavior of suspen-dome structures through both experiments and numerical analysis [6-14], and these research results have played an important role in suspen-dome constructions. However, with the development of researches and engineering practice, it is found that construction process may have a remarkable effect on the structural behavior of suspen-dome structures. The reasons induced the effect are mainly indicated on two aspects as follows: 1) There is a large pre-stressing loss induced by sliding friction between hoop cable and cable-strut joints during pre-stressing construction; 2) sliding cable-strut joint, recently used in suspen-dome, can be in any state during construction and service time, such as allow hoop cable sliding without friction, allow hoop cable sliding with any friction and don't allow hoop cable sliding and so on [15]. Therefore, it is important to study the effect level of above aspects on the structural behavior in order to give instruction to the suspen-dome structures application. 


\section{NUMERICAL SIMULATION METHOD OF CABLE SLIDING CONSIDERING FRICTION}

Before studying the effect of pre-stressing loss, a numerical simulation method, which can consider the sliding friction, must be found. From the published literatures, four methods is available: 1) coupling the degrees of freedom of hoop cable joint and brace strut lower joint and adjusting stiffness spring element in ANSYS software[13]; 2) modified original cable length method[14]; 3) frozen-heated method[9]; 4) cable-sliding criterion equation[16]. Considering the accuracy and time cost, the cable-sliding criterion equation is used to simulate the sliding friction.

The following is the general procedure to simulate the cable sliding considering the friction in ANSYS:

1) A finite element model is firstly established in ANSYS. Two-node LINK10 elements are adopted to simulate the cable member in suspen-dome structures without considering the sliding behavior between two sides of a cable-strut joint.

2) A nonlinear FE analysis is further conducted to obtain the tensions of all cable elements.

3) If the tensions of both side cables of a cable-strut joint are not in equilibrium, the cable may slide around the joint. The sliding lengths around each joint can be obtained by solving the cable-sliding criterion equations [16]. According to these sliding lengths around each joint, the virtual temperature of both sides of each joint can be evaluated using thermal expansion theory.

4) After that, a virtual temperature is applied to the corresponding cable element. A re-analysis on the suspen-dome structure is fulfilled to obtain the tensions of all cable elements.

5) Finally, the tensions of both sides of cable-strut joint are verified. If they are in equilibrium, the analysis is completed. If not, Step 3 through Step 5 is repeated until the equilibrium is achieved.

\section{EFFECT OF PRE-STRESSING LOSS INDUCED BY SLIDING FRICTION}

\subsection{The Studied Model}

In order to study the structural behavior of suspen-dome with sliding cable joint, a model was designed as shown in Fig. 1 and Fig. 2. This suspen-dome structure is with a span of $91.4 \mathrm{~m}$ and a rise of $17.03 \mathrm{~m}$. Steel pipes of $\phi 203 \mathrm{~mm} \times 6 \mathrm{~mm}, \quad \phi 219 \mathrm{~mm} \times 7 \mathrm{~mm}, \quad \phi 245 \mathrm{~mm} \times 7 \mathrm{~mm}$, $\phi 273 \mathrm{~mm} \times 8 \mathrm{~mm}, \quad \phi 299 \mathrm{~mm} \times 8 \mathrm{~mm}$ are used as the principal members of the upper single layer shell, and steel pipes of $\phi 219 \mathrm{~mm} \times 7 \mathrm{~mm}$ are used as vertical struts. Seven radial steel bars $(\phi 80 \mathrm{~mm})$ and seven hoop cables $(\phi 7 \mathrm{~mm} \times 121)$ are arranged in the bottom of the structure. The elastic modulus of steel and cable are $2.1 \times 105 \mathrm{~N} / \mathrm{mm} 2$ and $1.8 \times 105 \mathrm{~N} / \mathrm{mm} 2$, respectively. The boundary conditions are assumed to be pined. The inner hoop cable forces are uniformly $90 \mathrm{kN}, 140 \mathrm{kN}, 350 \mathrm{kN}, 540 \mathrm{kN}$, $630 \mathrm{kN}, 820 \mathrm{kN}, 1230 \mathrm{kN}$, when the gravity of steel members and the pre-stressing force were applied on the structure. 


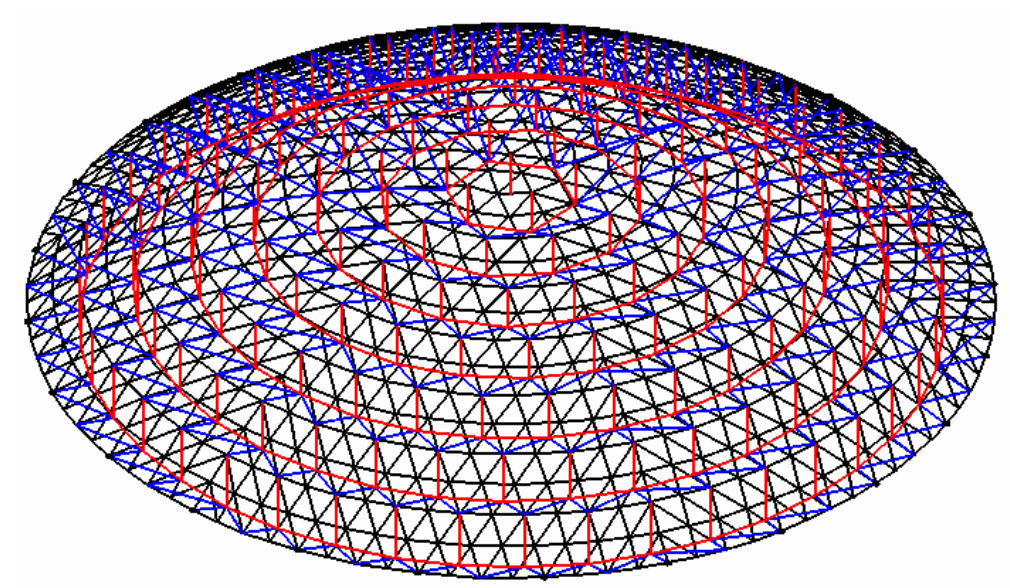

Figure 1. Axonometric View of Suspen-dome Structure

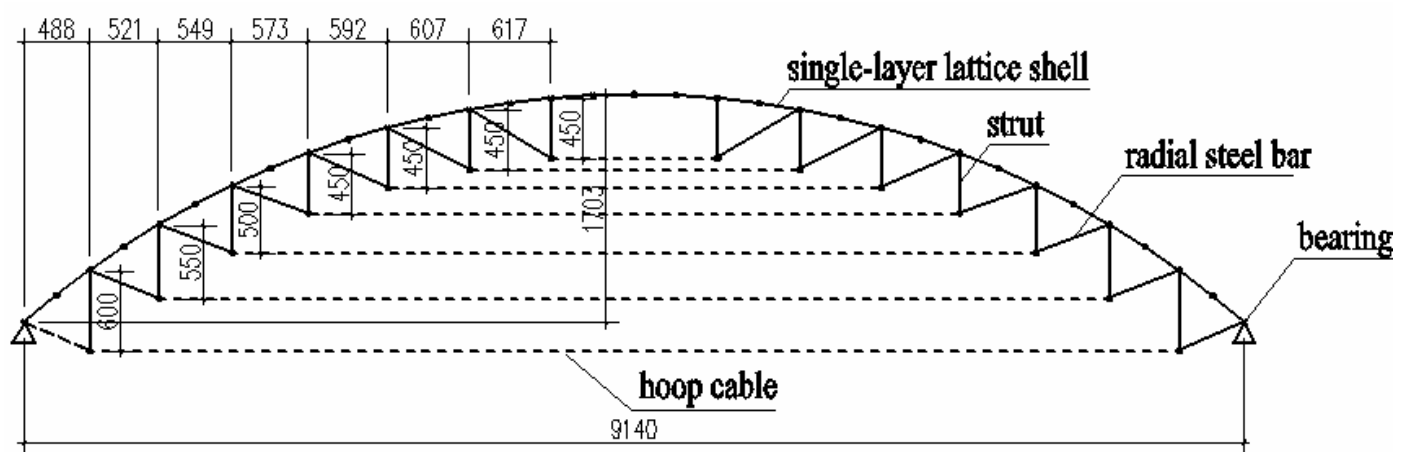

Figure 2. Sectional View of Suspen-dome Structure

\subsection{Result Analysis}

For the sake of convenient contrast, two construction schemes were studied. One scheme is considering the pre-stressing loss induced by sliding friction (hereinafter referred to as Case 1); the other scheme is not (hereinafter referred to as Case 2). Using the numerical method presented in section 3.1, the pre-stressing construction process was analyzed considering the sliding friction. In this analysis, only gravity and pre-stressing force were considered. And the sliding friction coefficient between hoop cable and cable-strut joint is assumed to be 0.40 based on the site monitoring [13].

For the case1, the maximum inner cable force, minimum inner cable force and the variance from design inner force are listed in Table 1. The inner hoop cable forces referring to Case 2 are also listed in Table 1. It can be seen that the inner cable force for each hoop cables are very no-uniform and the variance from design pre-stressing is up to $71.01 \%$ under Case 1 , which is induced by sliding friction. In the process of pre-stressing construction by pre-tensioning hoop cables, the pre-stressing of hoop cables away from the tension points was introduced by hoop cable sliding around cable-strut joint; if friction exists between hoop cable and cable-strut joint, the pre-stressing of hoop cable away from tension point is reducing. Therefore, it can be concluded that the sliding friction in pre-stressing construction of suspen-dome structures can induce notable variance. 
Table 1. Hoop Cable Force Distribution

\begin{tabular}{|c|l|r|r|r|r|r|r|r|}
\hline \multicolumn{2}{|c|}{ Cable groups } & \multicolumn{1}{c|}{1} & \multicolumn{1}{c|}{2} & \multicolumn{1}{c|}{3} & \multicolumn{1}{c|}{4} & \multicolumn{1}{c|}{5} & \multicolumn{1}{c|}{6} & \multicolumn{1}{c|}{7} \\
\hline \multirow{3}{*}{ Case 1 } & Minimum force $(\mathrm{kN})$ & 26.65 & 76.02 & 205.06 & 348.89 & 452.99 & 571.29 & 827.46 \\
\cline { 2 - 9 } & Maximum force $(\mathrm{kN})$ & 89.01 & 131.56 & 342.18 & 539.88 & 583.85 & 759.58 & 1127.50 \\
\cline { 2 - 9 } & Variance (\%) & 71.01 & 45.98 & 42.51 & 35.97 & 28.48 & 30.40 & 32.94 \\
\hline Case 2 & Cable force $(\mathrm{kN})$ & 91.95 & 140.72 & 356.66 & 544.92 & 633.37 & 820.84 & 1234.00 \\
\hline
\end{tabular}

Note: Cable group 1 is the innermost hoop cables, and Cable group 7 is the outmost hoop cables.

In order to investigate the variance of structural behavior between Case 1 and Case 2 in the service time, the static analysis of suspen-dome were carried out for both cases considering gravity, dead load $\left(1.0 \mathrm{kN} / \mathrm{m}^{2}\right)$ and live load $\left(0.5 \mathrm{kN} / \mathrm{m}^{2}\right)$ and pre-stressing force. Compared with the maximum equivalent stress of $88 \mathrm{MPa}$ and the maximum node displacement of $30 \mathrm{~mm}$ of Case 2 , the corresponding values of Case 1 are 126MPa (43.2\% increased) and $46 \mathrm{~mm}$ (53.3\% increased), respectively. Therefore, the pre-stressing loss induced by sliding friction during pre-stressing construction has a remarkable effect on the mechanical behavior of suspen-dome under dead load and live load.

The member number of upper single-layer latticed shell in the studied model in this paper is 3504 . The distribution of maximum equivalent stress in upper single-layer latticed shell for both Case 1 and Case 2 are given in Table 2. From Table 2, the member number of which the maximum equivalents stress is larger than $50 \mathrm{Mpa}$ is 771 in Case 2 and corresponding number in Case 1 is 1177, which is $52.66 \%$ more than that of Case 2. It is verified that the pre-stressing loss induced by sliding friction during pre-stressing construction has a remarkable effect on the mechanical behavior of suspen-dome in the service time again. Therefore, it is important that there is enough equipment and corresponding technical backup to reduce the pre-stressing loss induced by sliding friction during pre-stressing construction.

Table 2. Distribution of Equivalent Stress for Each Case

\begin{tabular}{|l|c|c|c|}
\hline & $0 \sim 50(\mathrm{Mpa})$ & $50 \sim 100(\mathrm{Mpa})$ & $\geq 100(\mathrm{Mpa})$ \\
\hline Case 1 & 2327 & 1088 & 89 \\
\hline Case 2 & 2733 & 771 & 0 \\
\hline
\end{tabular}

\section{EFFECT OF THE CABLE JOINT STATE}

For the new cable-strut joint referred in Section 1 during construction process, it can be locked by clamp plates and the hoop cables can not slide around cable-strut joint in this states; it also can be a state that allows the hoop cables to slide around cable-strut joint with friction. The above states can be obtained by controlling the pressure force between hoop cable and clamp plates. In order to obtain a good state for suspen-dome, it is needed to study the structural behavior of suspen-dome under any states. It is well known that the inner force of each hoop cables is nearly uniform under uniform loads, so the structural behaviors of suspen-some structure with any state of cable-strut joint have not obvious difference. However, there is obvious difference under asymmetrical load, such as half-span load. In this paper, the load combination of uniform load $\left(1.0 \mathrm{kN} / \mathrm{m}^{2}\right)$ and half-span load $\left(1.0 \mathrm{kN} / \mathrm{m}^{2}\right)$ was considered in the following analysis. 
Based on the pressure force between hoop cable and cable-strut joint, five cases are designed to study the structural behavior of suspen-dome under asymmetrical load:

Case 1: the hoop cables can slide around cable-strut joint with no friction.

Case 2: the hoop cables can slide around cable-strut joint with friction, and the friction coefficient is 0.15 .

Case 3: the hoop cables can slide around cable-strut joint with friction, and the friction coefficient is 0.30 .

Case 4: the hoop cables can slide around cable-strut joint with friction, and the friction coefficient is 0.45 .

Case 5: the hoop cables can not slide around cable-strut joint.

The member number of upper single-layer latticed shell in the studied model in this paper is 3504 . The distributions of maximum equivalent stress for each member in upper single-layer latticed shell for Case 1 to Case 5 are given in Table 4. The maximum equivalent stress and nodal displacement in upper single-layer latticed shell for Case 1 to Case 5 are given in Table 5.From Table 4 and Table 5, it is clear that:

1) The structural behavior of Case 5 (hoop cable can not slide around cable-strut joint) is best and Case 1(hoop cable can slide around cable-strut joint with no friction) is worst;

2) The friction coefficient between hoop cables and cable-strut joints is larger, the structural behavior of suspen-dome structures is better;

3) Compared with the maximum equivalent stress of 106MPa and the maximum node displacement of $26 \mathrm{~cm}$ of Case 5, the corresponding values of Case 1 are 216MPa (103.77\% increased) and 70 cm (169.23\% increased), respectively.

Therefore, it is clear that when the hoop cables can not slide around the cable-strut joints, the structural behavior of suspen-dome structures is best.

Table 3. Distribution of Equivalent Stress for Each Case

\begin{tabular}{|c|c|c|c|c|c|c|}
\hline Stress range (Mpa) & $0 \sim 30$ & $30 \sim 6$ & $60 \sim 90$ & $90 \sim 120$ & $120 \sim 150$ & $\geq 150$ \\
\hline Case 1 & 904 & 1644 & 626 & 172 & 64 & 94 \\
\hline Case 2 & 952 & 1817 & 501 & 118 & 74 & 42 \\
\hline Case 3 & 1162 & 1724 & 472 & 88 & 58 & 0 \\
\hline Case 4 & 1362 & 1740 & 360 & 42 & 0 & 0 \\
\hline Case 5 & 1143 & 1426 & 591 & 44 & 0 & 0 \\
\hline
\end{tabular}


Table 4. The Maximum Equivalent Stress and Nodal Displacement for Each Case

\begin{tabular}{|l|l|l|l|l|l|}
\hline & Case 1 & Case 2 & Case 3 & Case 4 & Case 5 \\
\hline maximum nodal displacement $(\mathrm{cm})$ & 70 & 57 & 47 & 40 & 26 \\
\hline maximum equivalent stress $(\mathrm{Mpa})$ & 216 & 182 & 149 & 116 & 106 \\
\hline
\end{tabular}

\section{CONCLUSIONS}

In this paper, a systematic study has been carried out in order to reveal the effect of construction process on the structural behavior of suspen-dome structures, and the following conclusions were obtained from the stability analysis results:

1) The pre-stressing loss induced by sliding friction during pre-stressing construction has a remarkable effect on the mechanical behavior of suspen-dome under dead load and live load.

2) The structural behavior of suspen-dome structure is different under asymmetrical load when the sliding friction coefficient between hoop cable and cable-strut joint is changing. When the sliding friction coefficient is large enough to make the hoop cable not sliding around joint, the structural behavior is the best case; when the sliding friction coefficient is equal to zero, the structural behavior is the worst case.

3) The construction process of suspen-dome structures has a remarkable effect on its structural behavior during service time under dead load and live load.

\section{ACKNOWLEDGEMENTS}

This work is sponsored by the Committee of National Natural Science Foundation of China (Grant No.: 50778122) and the Program for New Century Excellent Talents in University of Ministry of Education in China (Grant No.: NCET-06-0228).

\section{REFERENCES}

[1] Saitoh, M. and Okada, A., "The Role of String in Hybrid String Structure”, Engineering Structures, 1999, Vol. 21, No. 8, pp. 280-284.

[2] Mamoru Kawaguchi, M., Abe, M, Hatato, T., et al., "On a Structural System "suspen-dome” System”, Proc. of IASS Symposium, Istanbul, 1993, pp. 523-530.

[3] Chen, Z.H., Qiao, W.T. and Yan, X.Y., "Cable Supported Barrel Vault Structure System and Research on Mechanics Feature”, Advanced Steel Construction, 2010, Vol. 6, No. 3, pp. 867-878.

[4] Chen, Z.H., Liu, H.B., Wang, X.D., et al., "Review and Forecast of Suspen-dome Structures”, Journal of Building Structures, 2010, Supplementary Issue Vol. 1, pp. 210-215. [In Chinese]

[5] Zhang, Y.G., "Development of Cable-supported Structures in the Last Ten Years (2) : Application and Developments of Two-way Cable-supported Structures and Spatial Cable-supported Structures”, Industrial Construction, 2009, Vol. 39, No. 11, pp. 93-99. [In Chinese]

[6] Shi, K.O., Guo, Z.X. and Luo, B., "Method for Determining the Prestress of Elliptical Suspen-dome Structures”, China Civil Engineering Journal, 2010, Vol. 43, No. 9, pp. 88-98. [In Chinese] 
[7] Kang, W.J., Chen, Z,H. and Lam, H.F., et al., “Analysis and Design of the General and Outmost-ring Stiffed Suspen-dome Structures”, Engineering Structures, Vol. 25, 2003, pp. 1685-1695.

[8] Kitipornchai, S., Kang, W.J., Lam. H.F., et al., "Facters Affecting the Design and Construction of Lamella Suspen-dome Systems” Journal of Constructional Steel Research, 2005, Vol. 61, No. 6, pp. 764-785.

[9] Cui, X.Q. and Guo, Y.L., "Influence of Gliding Cable Joint on Mechanical Behavior of Suspen-dome Structures”, International Journal of Space Structure, 2004, Vol. 19, No. 3, pp. 149-154

[10] Cao, Q.S. and Zhang, Z.H., “A Simplified Strategy for Force Finding Analysis of Suspen-domes”, Engineering Structures, 2010, Vol. 32, No. 1, pp. 306-310.

[11] Zhang, Z.H., Cao, Q.S., Dong, S.L. and Fu, X.Y., "Structural Design of a Practical Suspen-dome”, Advanced Steel Construction, 2008, Vol. 4, No. 4, pp. 323-340.

[12] Zhang, A.L., Liu, X.C., Wang, D.M., et al., "Static Experimental Study on the Model of the Suspen-dome of the Badminton Gymnasium for 2008 Olympic Games”, Journal of Building Structures, 2007, Vol. 28, No. 6, pp. 58-67. [In Chinese]

[13] Wang, S., Zhang, G.J., Zhang, A.L., et al., “The Prestress Loss Analysis of Cable-strut Joint of the Badminton Gymnasium for 2008 Olympic Games”, Journal of Building Structures, 2007, Vol. 28, No. 6, pp. 39-44. [In Chinese]

[14] Zhang, G.F., Dong, S.L., et al., "Research on Sliding Cable in Construction of Suspen-dome Structures”, Journal of Zhejiang University (Engineering Science) 2008, Vol. 42, No. 6, pp. 1051-1057. [In Chinese]

[15] Liu, H.B., Chen, Z.H., "Influence of Cable Sliding on the Stability of Suspen-dome with Stacked Arches Structures”, Advanced Steel Construction, 2012, Vol. 8, No. 1, pp. 54-70

[16] Chen, Z.H., Liu, H.B., Wang, X.D. and Zhou, T., "Establishing and Application of Cable-Sliding Criterion Equation”, Advanced Steel Construction, 2011, Vol. 7, No. 2, pp. 131-143. 